\title{
RECONTEXTUALIZAČ̃O DO CURRÍCULO NACIONAL PARA O ENSINO MÉDIO DE FÍSICA NO DISCURSO DE PROFESSORES
}

\author{
Flavia Rezende * \\ Fernanda Ostermann ** \\ Josiane de Souza *** \\ Roberta Comissanha de Carvalho ****
}

RESUMO: Neste trabalho são analisados enunciados produzidos por 20 professores de física em uma atividade proposta durante um curso de extensão à distância. A partir da leitura de um texto acadêmico, os professores deveriam postar, em um fórum de discussão, um trecho do texto selecionado por eles juntamente com comentário e posicionamento. A análise buscou indícios de como os professores recontextualizam e se posicionam frente ao discurso acadêmico, ao discurso oficial e, principalmente, em relação ao projeto de currículo nacional. Foi possível identificar o posicionamento de 19 professores. A maior parte (13 professores) defendeu o currículo nacional, ainda que recontextualizado para atender à diversidade regional. Apenas seis se posicionaram contra a proposta curricular oficial, tendo criticado justamente seu "suposto" caráter de currículo nacional.

Palavras-chave: Recontextualização curricular. Currículo nacional. Professores de física.

\section{RECONTEXTUALIZATION OF NATIONAL CURRICULUM FOR TEACHING PHYSICS IN MIDDLE SCHOOL IN THE DISCOURSE OF TEACHERS}

ABSTRACT: In this paper we analyzed the discourse of twenty Physics teachers in an activity proposed in a training distance learning course. After reading an academic text, teachers should post in a discussion forum, an excerpt from the text selected by them, together with a commentary and postioning. The analysis sought evidence of how teachers recontextualize and position themselves in relation to the academic discourse, the official discourse, and especially in relation to the project of national curriculum. It was possible to identify the positioning of 19 teachers. The majority (13 teachers) defends the national curriculum though recontextualized to meet regional diversity. Only six are against the official curriculum proposal rightly criticizing their supposed character of national curriculum.

Keywords: Curricular recontextualization. National curriculum. Physics teachers.

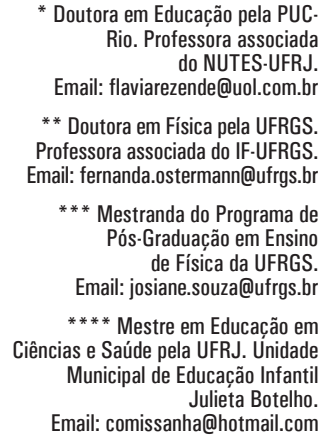




\section{PROBLEMATIZAÇÃO}

No fim da década de 90, o Brasil configurou-se como mais um país com um projeto de currículo nacional para o Ensino Médio, inserindo-se no contexto da adoção de políticas educacionais financiadas pelo Banco Interamericano de Desenvolvimento (LOPES, 2004). Os Parâmetros Curriculares Nacionais do Ensino Médio (PCNEM) (BRASIL, 1999) foram, então, lançados com o propósito de oferecer aos professores subsídios para a implementação, em todo o país, da reforma educacional proposta em 1996 pela Lei de Diretrizes e Bases da Educação Nacional (LDB). A reforma tinha como objetivo propiciar uma formação capaz de inserir as pessoas na estrutura social vigente e em seus processos produtivos (LOPES, 2002), representando, assim, um conjunto de saberes válidos para todos os brasileiros.

Lopes (2006) posiciona-se contra a adoção de um currículo nacional, visto que propostas desse tipo incorporam sempre a pretensão de homogeneizar, supondo que há padrões comuns e saberes universais a serem ensinados. Embora possam ser diferentes as finalidades desses saberes - aqueles voltados ao mercado de trabalho, à vida, a uma cidadania crítica, à formação de uma elite dirigente, a uma sociedade democrática, entre outros -, a autora critica a ideia de que exista um conjunto de saberes, senão garantidor, ao menos constituinte da possibilidade de chegar às finalidades pretendidas.

Para Lopes (2006), estamos vivendo hoje tempos de centralidade da cultura, e, por isso, a questão da diferença deve ser assumida como central. Nesse ponto, a autora é enfática ao criticar o projeto de cerceamento das diferenças a partir da adoção de uma cultura comum (tal como definida pelos PCNEM) e as finalidades sociais excludentes ditadas pelas exigências do mercado. Definir uma cultura comum seria, segundo a autora, pretender uma homogeneidade que mascara e silencia as diferenças. Assim, em vez de serem aceitas formas distintas de significar o mundo, esse projeto busca impor uma única forma ou uma maneira primordial de significação como a mais correta e a única capaz de alcançar as finalidades pretendidas, quer democráticas ou não (LOPES, 2006).

Em uma perspectiva contrária à de Lopes (2006) e defensora do currículo nacional, Tardif e Lessard (2008) consideram que os programas escolares são instrumentos cognitivos úteis, por contribuírem para homogeneizar as práticas e as organizações escolares, avaliar e comparar os conhecimentos transmitidos a todos os estudantes, além de serem capazes de unificar a ação coletiva dos docentes, admitindo que haja padrões comuns e gerais. Os autores reconhecem que, por outro lado, o professor atua como agente de transformações e improvisação e que possíveis imprecisões dos programas escolares muitas vezes exigem que os professores os interpretem dando-lhes algum sentido mais oportuno. Apesar de considerarem que há um grau de interpretação dos professores, os autores enfatizam que o saber escolar não é passado apenas como objeto cognitivo, mas através da imposição de uma cultura às pessoas, a qual é vista como privilegiada pela sociedade que cerca o ambiente escolar. 
$\mathrm{Na}$ área de ensino de ciências, as políticas educacionais ainda têm sido pouco discutidas, o que pode ser percebido nos principais eventos da área, pelo número reduzido de trabalhos inscritos nesta temática em comparação com outras. Embora pesquisadores da área tenham se envolvido com a elaboração dos PCNEM no fim da década de 90 e haja alguns trabalhos sobre a legislação, é preciso avançar nessa discussão. Talvez, justamente a falta de reflexão tenha como consequência o fato de que muitas pesquisas, ao se apropriarem destes documentos para validar ou justificar o trabalho, se voltem para o atendimento e a divulgação das propostas curriculares oficiais (REZENDE; OSTERMANN, 2005), sem questionamento sobre o que elas possam significar em termos de homogeneização ou imposição cultural.

Ricardo (2003) defende a concepção de currículo nacional e o entende como garantidor de qualidade do ensino de física, uma vez que, para o autor, os PCNEM prescrevem que o ensino médio deve não apenas preparar para o mercado de trabalho ou para o vestibular, mas formar um cidadão com ética, pensamento crítico e autonomia intelectual desenvolvidos. Para tanto, o documento apresenta três conceitos, entendidos como eixos estruturadores do currículo: competência, contextualização e interdisciplinaridade.

A concepção de ensino por competência, na perspectiva oficial, serviria ao professor como orientadora e instrumento de análise de suas práticas na busca por alcançar um ensino que cumpra com os objetivos do currículo nacional. A contextualização daria suporte para que o que se pretende ensinar tenha como ponto de partida e chegada a realidade do aluno, porém transcendendo o cotidiano. Como o objeto de estudo se torna complexo pela contextualização, o aluno é "obrigado" a reconhecer e ultrapassar os limites de uma única disciplina, a dialogar e confrontar outros conhecimentos para uma melhor compreensão do mundo, o que configuraria o terceiro eixo: a interdisciplinaridade.

Por sua vez, Ricardo e Zylbersztajn (2008), em um trabalho mais crítico, admitem o quanto as finalidades educacionais contempladas pelo discurso oficial aparecem associadas ao mundo do trabalho e atribuem ao currículo por competências o esvaziamento do conteúdo e a ênfase à dimensão profissionalizante, mas ainda parecem permanecer na posição em defesa do currículo nacional.

A ideia do presente trabalho foi levar esse debate a reais protagonistas do processo educativo na área das ciências da natureza, dirigindo-nos a professores de física de diversas regiões do Brasil. No contexto de um curso de extensão à distância sobre os PCNEM de física, proporcionamos uma discussão sobre este projeto de currículo nacional, que institui padrões de qualidade e saberes válidos para todos os sujeitos. Tomando por base a teoria de Bernstein (1996), procuramos identificar no discurso dos professores processos de recontextualização do projeto de currículo nacional e da proposta curricular oficial que poderiam conformar a prática pedagógica. 


\section{QUADRO TEÓRICO}

Ao realizar uma análise crítica do currículo e do processo de escolarização, Bernstein (1996) colocou em questão o papel da educação na reprodução cultural das relações de classe, tornando evidente que a pedagogia, o currículo e a avaliação são formas de controle social (MAINARDES; STREMEL, 2010). Para tal, baseou-se, principalmente, nos conceitos de código, dispositivo pedagógico e discurso pedagógico, nos princípios de classificação e enquadramento e no processo de recontextualização.

Bernstein (1996) interessou-se pelo processo de produção do discurso pedagógico de professores a partir das trocas que estabelecem com os diversos discursos que circulam no ambiente educacional. A concepção de que um discurso é responsável por estabelecer os princípios de ordenamento intrínsecos à produção, à reprodução e à mudança do discurso pedagógico é um dos principais aspectos de sua abordagem. De acordo com o autor, um discurso não representa apenas um texto ou um fenômeno linguístico, mas é articulado às práticas e às identidades dos sujeitos, assim como é submetido a mudanças e constituído enquanto repertório que conforma as relações sociais.

O dispositivo pedagógico, construído em analogia com o dispositivo linguístico, corresponde a um conjunto de regras discursivas hierarquicamente relacionadas, denominadas distributivas, recontextualizadoras e avaliativas, que compõem a gramática intrínseca do discurso pedagógico e regulam a comunicação pedagógica (BERNSTEIN, 1996). Através dessas regras, o dispositivo pedagógico fornece a gramática intrínseca do discurso pedagógico, que, para o autor, é um princípio de recontextualização de outros discursos que serão seletivamente transmitidos e adquiridos. As regras distributivas tratam especificamente do campo de produção do conhecimento acadêmico, e as regras avaliativas, subordinadas às recontextualizadoras, referem-se exclusivamente à avaliação da aprendizagem realizada na prática pedagógica.

As regras recontextualizadoras, relevantes para o presente estudo, que investiga o discurso dos professores aproximado do discurso pedagógico, caracterizam o discurso pedagógico em si e relacionam-se ao processo de recontextualização. Este processo consiste no movimento de um discurso de seu contexto original de produção para outro contexto onde é modificado e relacionado a outros discursos e, depois, é reposicionado (BERNSTEIN, 1996) - textos transferidos do campo acadêmico para o contexto oficial de um Estado ou do contexto oficial para as escolas podem ser bons exemplos. Cada um desses contextos é reinterpretado como um campo recontextualizador, que tem como principais atividades "criar, manter, mudar e legitimar o discurso, a transmissão e as práticas organizacionais que regulam os ordenamentos internos do discurso pedagógico” (BERNSTEIN, 1996, p. 271).

É importante ressaltar que o processo de recontextualização produz uma mudança no discurso devido à influência da ideologia, sujeita a diferentes visões de mundo e aos interesses especializados e/ ou políticos dos agentes 
recontextualizadores, cujos conflitos estruturam o campo recontextualizador, intermediário entre o campo de produção e o campo de reprodução do discurso, as escolas.

São dois os campos recontextualizadores identificados por Bernstein (1996). O primeiro diz respeito ao Campo de Recontextualização Oficial (CRO), criado, composto e gerenciado pelo Estado e dependente dos discursos ideológicos e políticos dominantes. O CRO mantém relações estreitas com o campo internacional, constituído prioritariamente por agências financiadoras internacionais e por outros Estados nacionais, com o campo de produção, relacionado à esfera econômica, e com o campo de controle simbólico, ligado à esfera cultural.

O Campo de Recontextualização Pedagógica (CRP), ou não oficial, relativamente autônomo, é entendido como o campo de produção de teorias educacionais que orientam a prática pedagógica, sendo constituído por pesquisadores em educação de forma geral, pela universidade e por eventos e periódicos especializados. A recontextualização pedagógica se dá justamente por meio da relação entre o CRO e o CRP nos processos de transferência de um contexto a outro, sendo o CRP responsável por gerar "as posições da teoria, da pesquisa e da prática pedagógica” (BERNSTEIN, 1996, p. 271).

Ao ser apropriado por agentes recontextualizadores, um texto passa por transformações reguladas por um processo de descontextualização, que se refere a mudanças no texto produzidas por meio de seleção, simplificação e elaboração, que resultam em seu reposicionamento e refocalização (BERNSTEIN, 1996). Advindos ou não da esfera oficial, os textos são fragmentados, sendo algumas de suas partes mais valorizadas em detrimento de outras e associadas a outras partes de textos capazes de ressignificá-los e reposicioná-los.

O processo de recontextualização se dá em meio a conflitos de diferentes interesses, que estruturam os campos recontextualizadores e expressam movimentos ideológicos que regulam o novo posicionamento ideológico do texto em seu processo de relocação no campo de reprodução do discurso. Uma vez naquele campo, o texto transformado sofre nova transformação ou reposicionamento adicional assim que se torna ativo no processo pedagógico.

Para Bernstein (1996), quando os campos recontextualizadores oficial e não oficial se associam, mais facilmente se exerce o controle sobre o que acontece nas escolas. No entanto, se houver uma autonomia relativa entre esses dois campos, origina-se uma arena de luta, que facilita a criação de espaços para as escolas trabalharem em uma direção questionadora dos padrões estabelecidos. Por isso, Bernstein (1996) afirma que todo discurso pedagógico é uma arena de conflito e, potencialmente, de mudança. 


\section{PROCEDIMENTOS METODOLÓGICOS}

\section{Contexto e sujeitos da pesquisa}

O contexto desta pesquisa é um curso de extensão à distância para formação continuada de professores de física de nível médio oferecido em um ambiente virtual ao longo de dez semanas. O curso abordou os PCNEM e os objetivos do ensino de física, tendo como recursos pedagógicos a leitura de textos acadêmicos e a participação em fóruns de discussão com a orientação de tutores e em atividades que envolviam o posicionamento dos professores a partir da leitura e da interação com os colegas e com os tutores.

O grupo era composto por 20 professores oriundos de todas as regiões do Brasil, sendo 16 do gênero masculino e quatro do gênero feminino. Dos participantes, 14 cursaram a graduação em instituições públicas. Todos lecionam física para o ensino médio, e a maioria, exclusivamente para esse nível de ensino; em relação ao tempo de atuação no magistério, o grupo variava dos recém-formados àqueles com mais de 20 anos de experiência. Quanto às instituições em que lecionam, 12 professores trabalham em escolas públicas; cinco, em instituições privadas; dois, em ambas; e um professor optou por não declarar onde leciona.

Ainda que o discurso dos professores esteja relacionado a aspectos socioculturais listados no parágrafo anterior, neste trabalho, não temos a pretensão de investigar estas relações, por considerarmos que, para tal, seria necessário outro estudo, que incluísse procedimentos metodológicos como, por exemplo, entrevistas e até mesmo a observação participante das realidades particulares em que esses sujeitos estão inseridos.

O corpus analisado neste estudo é composto de enunciados produzidos pelos professores em uma das atividades propostas no curso à distância, na qual eles deveriam postar, em um fórum de discussão, um trecho selecionado por eles de um texto acadêmico (LOPES, 2006) juntamente com um comentário concordando ou discordando da posição da autora ou de outro autor citado no texto.

No texto em questão, Lopes (2006) delineia inicialmente um panorama de institucionalização de políticas curriculares em países tais como Inglaterra, Nova Zelândia, EUA e Espanha e ressalta que, apesar de todas as diferenças quanto ao período histórico e à intenção na implementação do currículo, um ponto de interseção entre os projetos é a ideia de que existe um conjunto de saberes constituinte da possibilidade de atingir as finalidades pretendidas para uma educação de qualidade. Esse conjunto comum de saberes parte da ideia de cultura comum e é constituinte de projetos de disputa política. Lopes (2006) salienta que alguns autores, como Michael Apple (1994, citado por Lopes, 2006), Gimeno Sacristán (1998, citado por Lopes, 2006) e Raymond Williams (1984, citado por Lopes, 2006), apesar de criticarem o caráter excludente dos objetivos educacionais defendidos pelo projeto de currículo nacional, veem a importância da existência de uma cultura comum visando a finalidades democráticas. Contrariamente a esta posição, a autora argumenta que grupos com características socioculturais 
e políticas semelhantes possuem saberes diversos, construídos ao longo de histórias de vida diversas. Outra crítica feita pela autora é que, segundo ela, não há necessidade de se ter o currículo como um regulador da prática e da atuação do professor em sala de aula, já que diversos outros mecanismos sociais já regulam a cultura e o currículo. Lopes afirma que as ações curriculares governamentais seriam mais produtivas se não colocassem a prática curricular em determinada direção, mas, sim, favorecessem condições para mudanças nas múltiplas direções em que as práticas se estabelecem.

Ainda de acordo com Lopes (2006), o projeto de currículo nacional permanecia vigente no Brasil naquele momento - por meio das diretrizes nacionais, dos parâmetros para o ensino fundamental e para o ensino médio e das orientações curriculares nacionais -, uma vez que o Estado ainda se encontrava submetido a restrições econômicas impostas por agências internacionais ${ }^{1}$. Essas restrições, segundo a autora, fazem parte de um processo de constituição de uma cultura capaz de engendrar concepções em defesa do currículo nacional em grupos políticos de marcos ideológicos bem distintos, ou, como caracterizado por Ball (2004, citado por Lopes, 2006, p. 142-143), trata-se da construção de um discurso político internacional "considerado infalível para resolver os problemas econômicos nacionais: valorização do mundo globalizado, processos de avaliação com base em princípios de mercado, foco na formação do trabalhador flexível e polivalente".

A consolidação desse discurso internacionalmente estaria associada à ação de comunidades epistêmicas (internacionais e locais) formadas por consultores internacionais, empresários, produtores de livros e documentos que compartilham concepções, valores e regimes de verdade comuns e que operam nas políticas pela posição que ocupam frente ao conhecimento. Esses grupos estabelecem relações entre poder e saber que intervêm na elaboração e na implementação das políticas públicas ligadas à educação no país, bem como atuam como um canal pelo qual novas e redentoras ideias circulam das sociedades para o governo e de um país para outro.

\section{Objetivo e questão de pesquisa}

O presente estudo se caracteriza como uma pesquisa qualitativa que busca construir conhecimento a partir da análise do discurso dos sujeitos participantes. Na situação estudada, os professores elaboram discursivamente perspectivas a partir de um discurso acadêmico no contexto de um curso oferecido pela universidade, sendo considerados, assim, participantes do CRP e agentes de processos de recontextualização tais como descritos por Bernstein (1996).

Consideramos que, ao destacarem e comentarem trechos do texto acadêmico utilizado na atividade, os professores realizaram processos de recontextualização das ideias discutidas no âmbito acadêmico. A partir deste entendimento, buscamos indícios de como os professores recontextualizaram e se posicionaram frente ao discurso acadêmico, ao discurso oficial e, principalmente, em relação ao projeto de currículo nacional e/ou à proposta curricular oficial. 
Formulamos as seguintes questões para orientar a pesquisa: como os professores elaboraram discursivamente processos de recontextualização de um projeto de currículo nacional e/ou da proposta curricular oficial? Que posicionamentos resultaram desses processos?

\section{Procedimentos de análise}

Buscamos identificar processos de recontextualização em fragmentos do discurso dos professores tanto quando se referiram ao currículo nacional (ou a expressões equivalentes, como "saberes comuns", "cultura comum”) quanto quando mencionaram explicitamente os documentos oficiais. No interior desses fragmentos, tentamos identificar movimentos de descontextualização, reposicionamento e refocalização, além do posicionamento ideológico dos professores no fim do processo.

A análise seguiu a ordem de participação dos professores no fórum. O primeiro a participar foi denominado P1, o segundo, P2, e assim consecutivamente. São apresentados, ao longo da análise, as partes do texto destacadas e os comentários dos professores, objetos da análise dos processos de recontextualização. Os comentários apresentados são reproduções dos enunciados dos professores e estão sujeitos a adaptações para publicação. Não foi nossa intenção estudar a interação discursiva entre os participantes, o que exigiria outros conceitos e procedimentos de análise.

\section{PROCESSOS DE RECONTEXTUALIZAÇÃO CURRICULAR NO DISCURSO DOS PROFESSORES}

No início do fórum, P1 destaca e, assim, descontextualiza a seguinte ideia de Gimeno Sacristán (1998, citado por LOPES, 2006, p.135):

Em uma perspectiva crítica de currículo, o projeto de uma cultura comum pode contribuir, como afirma Gimeno Sacristán (1998), para a igualdade de oportunidades, sendo referencial de qualidade mínima exigida. Para tal, afirma o autor, a deliberação sobre o currículo deve ser democrática e não deve pretender definir a prática ou seus conteúdos em todos os detalhes.

Ao concordar com o autor e agregar à sua ideia a realidade escolar, P1 reposiciona o discurso oficial, que não foi proposto inicialmente enquanto referencial de qualidade mínima. Refocaliza este referencial ao separá-lo de uma definição da prática e do conteúdo pedagógicos. Posiciona-se, assim, a favor de uma proposta curricular oficial recontextualizada em função das diversidades, contrária à regulação da prática docente e dos conteúdos a serem trabalhados em sala de aula:

Concordo com a ideia de que se tenha um referencial de qualidade mínima exigida, mas sem definir a prática ou seus conteúdos em todos os detalhes. Defendo que o professor deve ter uma formação muito boa, de modo que, sabendo o referencial de qualidade mínima exigida e o conteúdo a ser ensinado, ele possa definir 
para cada uma de suas classes como será a sua prática, visto as diversidades que encontramos em cada uma delas. Tentar imputar a prática é não conhecer uma escola na realidade e não observar as diversidades com que nós, professores, nos defrontamos. (P1)

P2 comenta o mesmo trecho destacado por P1 e também defende a autonomia do ato educativo, mas reposiciona esta ideia quando critica a imposição do currículo oficial e refocaliza a qualidade relacionando-a diretamente ao trabalho dos professores:

Bom, eu, como professor, critico muito este currículo imposto e concordo com a colega acima na escolha do texto, pois a democracia deve valer a partir do momento que escolhemos ministrar as nossas disciplinas e interagir com os nossos alunos. Qualidade somos nós, que fazemos surgir; tudo ao nosso redor contribui para este processo de qualidade e escolhas dentro da instituição de ensino. Fazemos parte desta exposição de teoria e prática para com os alunos e para com a instituição. A nossa escolha é definida no momento em que acreditamos que podemos ensinar o outro com base em nossos próprios conhecimentos [...]. (P2)

Com base no mesmo trecho, P3 retoma o reposicionamento do discurso oficial construído por P1, considerando-o também como um referencial de qualidade mínima, e agrega outros elementos. Refocaliza, assim, esse referencial enquanto "base para medir o conhecimento e o desenvolvimento do povo brasileiro" (P3) e como norteador de qualidade a ser complementado com elementos regionais:

Em particular, a colega [P1] coloca muito bem quando diz que nós temos que ter um mínimo de referencial de qualidade... ou, sem isso, poderíamos estar vivendo num mesmo país e, apesar disso, agravaríamos situações tais que seria como se vivêssemos em mundos diferentes. Sem uma base curricular, seríamos um estranho no ninho. Cada escola viveria um mundo diferente, e, assim, como aconteceria uma avaliação que servisse de base para medir o conhecimento e o desenvolvimento do povo brasileiro? [...] Se o ensino não for composto por uma qualidade mínima de referência, em bem pouco tempo, nós nos tornaremos uma verdadeira torre de Babel. [...] Por isso tem que haver um mínimo de qualidade para que possamos tomar como um norteador, e os demais complementos viriam como complementos regionais. (P3)

P4 considera o mesmo trecho destacado por P1 e o comentário de P3. Possivelmente, P4 descontextualiza a parte do comentário em que P3 menciona a "base para medir o conhecimento e o desenvolvimento do povo brasileiro" e refocaliza agora o trecho do texto reposicionado como qualidade mínima por P1 e P3, enquanto referencial teórico e prático. Ainda o refocaliza como base para a compreensão das dificuldades sociais, que, segundo ele, seriam as mesmas em todo o país. Assim, esse professor recontextualiza a proposta oficial considerando-a um instrumento capaz de homogeneizar saberes que servirão para a promoção de discussões sobre os problemas nacionais: 
Concordo com o ponto levantado pelo colega P3. É imprescindível que se tenha um referencial teórico e prático, para que possamos compreender, intervir e participar ativamente da sociedade. Sem essa base comum, como, por exemplo, poderemos participar de debates e propor soluções para nossos problemas? Apesar de vivermos em regiões diferentes e ter hábitos e costumes específicos, temos em comum as mesmas dificuldades e aspirações. (P4)

P5 também se refere ao mesmo trecho comentado pelos colegas e se coloca a favor de um referencial curricular comum, como defendido por P4, mas o reposiciona em termos de um padrão a partir do qual poderão ser feitas comparações e juízos de valor. Contudo, por reconhecer que as particularidades de cada região do país configuram dificuldades educacionais específicas, questiona se um mesmo currículo poderia atendê-las:

Concordo com você [P4], com a necessidade desse referencial, pois é a partir de determinados padrões que poderemos estabelecer relações de comparações e atribuir juízos de valores. Mas, em um ponto, tenho dúvida e não posso discordar nem concordar: sendo o Brasil tão grande - e estou no Amazonas, onde temos características bem distintas do resto do país -, será que temos as mesmas dificuldades? E, se não temos, essa base curricular comum atende realmente a essas necessidades tão específicas? (P5)

P6 destaca a relação entre currículo e cultura na ideia de Williams (1984, citado por LOPES, 2006, p. 137-138), a partir de trecho incluído no fórum por P4, após a sua primeira participação analisada acima:

Os saberes não são sistemas de informação ou conjuntos reificados de conhecimentos, mas produções culturais. Selecionar um corpo de saberes como capaz de compor uma cultura comum e transmitir essa cultura implica interpretar tais saberes, associá-los a determinadas práticas e instituições específicas e obrigatoriamente reconstruí-las, produzindo novas culturas (WILLIAMS, 1984, citado por LOPES, 2006, p. 137-138).

A professora reposiciona esta ideia ao associá-la a dificuldades de transmitir determinados conhecimentos dadas as diferenças regionais. Quando afirma no fim de seu enunciado que "devemos utilizar essas informações em nosso favor", parece que ela está se referindo às informações particulares de cada cultura e refocalizando, assim, a ideia de cultura comum (ou de currículo nacional):

[...] em se pensar conhecimento desvinculado da cultura, criam-se muitas dificuldades na transmissão de determinados conhecimentos, pois cada comunidade, região, estado, etc. tem suas particularidades, por isso devemos utilizar essas informações em nosso favor, para facilitar a atuação no âmbito escolar. (P6)

A interpretação feita do discurso de P6 parece adequada quando a professora posta, em seguida, o trecho "[...] há a necessidade de uma cultura comum e de uma educação igualmente democrática capazes de superar padrões sociais e educacionais vigentes com base em uma estrutura de classes suposta 
como imutável" (WILLIAMS, 1984, citado por LOPES, 2006, p. 136), parecendo, com essa ideia de Williams, justificar seu comentário.

P7 descontextualiza outra ideia de Williams (1984, citado por LOPES, 2006, p. 135), segundo a qual "a seleção de conteúdos curriculares é sempre uma seleção particular da cultura, produto de ênfases e omissões, organicamente relacionadas às escolhas e às finalidades mais amplas da educação", e a reposiciona ao associá-la à afirmação de que esta seleção particular da cultura privilegiou e continua privilegiando as classes dominantes e quem detém o poder. A partir deste reposicionamento, $\mathrm{P} 7$ refocaliza o currículo comum associando-o à exclusão. Conclui sua participação recontextualizando criticamente o currículo, considerando-o uma seleção particular da cultura a qual exclui. Nesse ponto, acaba por se opor à proposta de um currículo nacional:

Realmente, o currículo é uma seleção particular da cultura, bem particular, que, durante muito tempo, privilegiou e continua privilegiando, de maneira velada, as classes dominantes e quem detém o poder. Antes, tínhamos uma escola para poucos e muitos excluídos. Bem, hoje temos uma escola para todos, mas que continua a excluir. (P7)

P8 se refere ao trecho incluído no fórum por P6 e concorda com este participante, admitindo que "realmente a cultura deve ser comum", defendendo, portanto, a existência de um projeto de currículo nacional. A partir daí, reposiciona este, atribuindo-lhe o papel de promover o acesso de todos à educação, bem como a possibilidade de ascensão social e cultural. Assim, P8 recontextualiza o currículo nacional equiparando-o à educação, considerada dever do Estado e direito de todos:

Olá, P6, excelente sua escolha de texto, realmente a cultura deve ser comum, e a educação, democrática em atendimento ao princípio da isonomia: tratar os desiguais na exata medida de suas desigualdades, com a finalidade de se obter ao final a igualdade pretendida. Esse texto demonstra claramente esta ideia, porque, se assim procedido, estaremos rompendo com as estruturas sociais "supostamente imutáveis" que estão sob o manto do capital. Portanto, a educação é a ferramenta de distribuição igualitária de uma cultura que deve ser comum, porque vivemos num país democrático e negá-la seria um paradoxo, a despeito de vermos na prática a brutal dissociação dessa ideia, que se calca numa pseudodemocracia por razões de prevalência do capital. Cabe, portanto, à educação romper as barreiras e permitir a ascensão cultural e social como um todo, porque ela é dever do Estado e direito de todo cidadão. (P8)

P9 destacou o seguinte trecho: "Selecionar um corpo de saberes como capaz de compor uma cultura comum e transmitir essa cultura implica interpretar tais saberes, associá-los a determinadas práticas e instituições específicas e obrigatoriamente reconstruí-los, produzindo novas culturas" (LOPES, 2006, p. 138). O professor reposiciona a ideia de cultura comum questionando sua viabilidade em um país extenso e diverso como o nosso. Ele finalmente refocaliza o currículo comum como uma preparação para que os alunos possam abstrair o conhecimento e produzir uma cultura intermediária: 
[...] a seleção de conteúdos busca uniformizar os saberes ensinados no Brasil. Devido à sua extensão e a realidades diferentes, vejo que é difícil uniformizar tal nação e que, devido às realidades, ao fato de os variados Estados serem diferentes, temos que preparar nossos alunos de modo que eles possam, em qualquer lugar a que chegarem, conhecer e entender toda a realidade do lugar, ou seja, estar preparado para abstrair o conhecimento que lhe é oferecido, para que, a partir de então, possa "produzir" uma cultura intermediária. (P9)

P10 destaca o mesmo trecho que P9, mas inclui a frase seguinte: “Ou seja, o próprio processo de construir uma cultura entendida como comum produz uma pluralidade cultural que nega a cultura comum" (LOPES, 2006, p. 138). A partir daí, ele reposiciona a ideia de cultura comum - e, portanto, de um currículo comum -, chamando atenção para a insuficiência desse processo frente aos exames oficiais, como o Enem. Conclui seu processo de recontextualização se posicionando contra esta ideia, atentando para a persistência das diferenças regionais, setoriais e nas condições de formação das escolas e em suas "culturas de ensino":

Buscando oportunizar o acesso a todos, a partir de conteúdos que são discutidos nas escolas de todo o território nacional e da unificação da seleção de vagas em uma única data e hora e possibilitando uma disputa aberta, valendo sua pontuação para qualquer localidade do país, o novo modelo do Enem efetiva o desejo de processo comum. A seleção está garantida a todos, concordo. Entretanto, a formação desses alunos, a partir de agora, partirá de uma cultura "comum" para uma cultura "específica". Estaremos voltados para discussões comuns, de assuntos comuns, mas a forma de se trabalhar o aluno preparando-o para este exame tem características regionais, setoriais. As diferenças continuarão existindo, pois as condições das escolas das diferentes regiões são bem distintas. Algumas poderão direcionar e formar melhor seus alunos. As culturas de ensino também são distintas. (P10)

P11 dá continuidade à discussão sobre a seleção dos conteúdos cobrados no Enem. Reposiciona a discussão levantada por P10 ao colocar em foco a disputa entre os conteúdos do Enem selecionados por "professores universitários" e a cultura local ("da região ou do Estado"). Com esse comentário, P11 refocaliza a questão dos exames nacionais considerando que os mesmos menosprezam a realidade cultural e social às quais os estudantes estão submetidos e, em função disso, vê como utópico um mesmo ensino para todo o território nacional. Por meio de um enunciado claramente questionador, P11 coloca em xeque as finalidades dos PCNEM e dos exames oficiais, acusando os parâmetros de terem a pretensão de homogeneizar as culturas e os saberes dos alunos bem como os exames nacionais de servirem apenas como índice para estabelecer um ranking entre os Estados:

[...] Concordo, mas como deveria ser feita esta escolha? Através apenas de professores universitários que não conhecem a realidade das nossas salas de aula? Ou algo colaborativo, em que um grupo de professores universitários e de escola particulares e públicas estivesse dialogando para uma melhoria em nossa educação como um todo, mas, primeiro, respeitando a nossa cultura local (digo da região ou do Estado)? Nossa cultura local é algo 
muito rico para tentarmos, num primeiro momento, criar uma identidade local. Depois podemos dialogar com o resto do país e, assim, mostrar que as diferenças culturais são responsáveis, para que tenhamos realmente uma cultura democrática. Agora, como propor isso fica difícil, mas deveria ser um dos fatores para se levar em conta. Quando falamos em processo seletivo, é um processo excludente. Como tal, deve querer selecionar os melhores, não importando se sua aprendizagem foi em escola pública ou particular? O ensino deve ser o mesmo em todo o território nacional, triste utopia. Condições das escolas, também. Assunto para muitos e muitos debates. [...] Para que servem, afinal, os PCNEM? Para uma maior homogeneidade da cultura e dos saberes do aluno? Ou verificar através dos exames qual Estado ou região do Brasil está mais bem-formado culturalmente? (P11)

P12 descontextualiza a ideia de universalização de saberes, presente na fala de P11, e a reposiciona como algo que não representa uma dificuldade, principalmente para a física, considerada por ele como saber universal. Fica mais claro seu posicionamento em defesa do currículo nacional quando considera que a universalização de saberes já estaria solucionada nos livros didáticos e nos currículos. Refocaliza a questão dirigindo sua preocupação para a prática metodológica. Ao mencionar, ao fim, as intenções que buscam "valores e cultura", parece não se afastar, em sua recontextualização, de seu compromisso com o currículo nacional.

Com relação à universalização de saberes, em âmbito nacional, seria fácil para as disciplinas de exatas, uma vez que estas são universais. Acredito que a imposição dos saberes referentes à nossa disciplina, física, não é a maior dificuldade que se apresenta, mas, sim, a forma de apresentar os conteúdos, tanto nas escolas de ensino quanto nas faculdades. Os conteúdos já estão uniformizados e são apresentados nos livros didáticos e nos currículos para o ensino básico. Precisa-se da permanente construção da prática metodológica e que esta esteja direcionada a intenções que busquem valores e cultura. (P12)

P13 diz concordar com o fim do comentário de P12, o que indica o mesmo posicionamento, a recontextualização do currículo nacional em favor de "valores e cultura". Ao dar sentido a esta ideia, P13 agrega a ela o papel que atribui à física, "em especial", de igualar o mundo e melhorar a vida de todos. Entretanto, mais adiante, discorda da ideia de que o livro didático uniformiza os conteúdos de física, já que o considera apenas um coadjuvante da prática docente. Essa discordância poderia dar margem a supormos que ele também recontextualiza a uniformidade do currículo nacional, o que não é confirmado no fim de seu enunciado, quando refocaliza a busca de práticas eficazes e o dever de democratizar os conhecimentos sedimentados pela humanidade:

Concordo com o P12 no que diz respeito a direcionar as intenções na busca de valores e culturas. De certo que a física, em especial, traz no seu bojo um arsenal de saberes que inevitavelmente estarão a serviço de todos algum dia e em algum tempo. Isso faz com que tenhamos nas mãos uma poderosa arma para equipar o mundo e fazer com que a vida de todos melhore. Porém, discordo da afirmação de que os conteúdos de física estejam uniformizados, uma vez que não acredito 
na ditadura do livro didático. Não somos, enquanto professores, reféns do livro didático. Temos várias formas de trabalhar e, nestas, o livro didático é um mero coadjuvante, que poderá ou não ser utilizado. A busca de práticas educativas mais eficazes e eficientes perpassa por uma pesquisa incessante por parte de todos nós, que temos o dever de democratizar os conhecimentos sedimentados pela humanidade. (P13)

P14 reflete sobre os interesses políticos por trás da defesa do currículo nacional, dos exames nacionais e de uma cultura comum. Reposiciona esta ideia relacionando-a às comunidades epistêmicas, abordadas por Lopes (2006), embora não destaque nenhum trecho do texto. Refocaliza, assim, a ideia de currículo comum ao reconhecer que haveria uma parte oculta na proposta das Diretrizes Curriculares Nacionais do Ensino Médio (DCNEM) e dos PCN, atribuída por ele à abordagem sobre as comunidades epistêmicas, que não é discutida na escola. Com essa construção, P14 recontextualiza, por oposição, a apropriação ingênua dos PCNEM pela escola:

A serviço de qual projeto político estão a unificação curricular, as avaliações centralizadas e o projeto de cultura comum? Muito interessante a abordagem feita sobre as comunidades epistêmicas. A leitura do texto me fez conhecer o outro lado, a parte oculta da proposta das DCEM e dos PCNEM. Nas escolas, as discussões giram em torno das competências e das habilidades, o que, por sinal, gera uma confusão danada, e, quanto às dificuldades encontradas para a aplicação dos PCN através de projetos interdisciplinares e outras atividades, raramente discutimos sobre o currículo como proposto no texto. (P14)

P15 destaca um trecho do comentário de P11 que questiona a função dos PCN, e, a partir daí, seu comentário tenta responder a esse questionamento. P15 destaca a homogeneidade como função dos PCN e reposiciona esta função como algo com que concorda. No entanto, admitindo que essa homogeneidade não seria possível, devido à diversidade cultural do país, P15 recontextualiza a proposta sugerindo abordagens e recursos didáticos que levem em conta as características culturais de cada região:

Gostei muito quando P11 coloca: "Para que servem, afinal, os PCN, para uma maior homogeneidade da cultura e dos saberes do aluno? Ou verificar através dos exames qual Estado ou região do Brasil está mais bem-formado culturalmente?". Os PCN foram criados e, de fato, não se tornaram um documento que deveria ser, na minha opinião, obrigatório no planejamento de ensino, e não utilizado como um suporte. Bem verdade que os $\mathrm{PCN}$ servem, de certa forma, para uma homogeneidade, ou seja, um padrão para o ensino público, pois, em sua proposta, podemos perceber que é um documento bem-elaborado e que visa ao cotidiano do indivíduo. O que temos que considerar é que, no Brasil, a homogeneidade do ensino não é algo fácil de se alcançar (acredito que impossível) [...], devemos levar em conta que cada Estado possui uma cultura, ou seja, um hábito de vida diferente, e um livro que foi elaborado por uma pessoa da região Sul, por exemplo, talvez não seja apropriado para ser aplicado aqui, na Bahia, a menos que o autor conheça bem a região. $\mathrm{O}$ que estou querendo dizer é que não acho que os recursos didáticos não devem ser os mesmos para todo o país, mas que seja adaptado para cada região, trazendo exemplos do dia a dia das pessoas. (P15) 
P16 destaca do texto o conceito de "comunidade epistêmica" proposto por Antoniades (2003, citado por LOPES, 2006, p. 144):

O conceito de comunidades epistêmicas foi construído com a intenção de entender as influências sobre o Estado exercidas por grupos de especialistas, não exclusivamente cientistas, mas também políticos, empresários, banqueiros, administradores. Busca, portanto, situar as relações entre saber e poder que intervêm nas políticas, especialmente no contexto das relações internacionais, estando associado a uma concepção de política como produção para além das ações do Estado, sem, no entanto, desconsiderar o Estado como atuante no processo.

A partir deste destaque, a professora reposiciona o texto ao apontar a necessidade de identificar os "grupos de especialistas" responsáveis pela definição das diretrizes e dos parâmetros, ponto que levaria também à questão do "quem defende os PCN" e "por que e para que defendem":

[...] considero de grande valor identificar e esclarecer esses "grupos de especialistas" influentes na política. Particularmente na política voltada para a educação e o ensino, tal definição elucida a questão sobre quem apresenta as novas diretrizes ou parâmetros e como esses são discutidos e estabelecidos. Isso leva ainda à questão de "quem defende os PCNEM" e, por outro lado, "por que e para que defendem", uma vez que sabemos que os professores e os alunos, ainda que atores principais, não são vistos individualmente, em suas particularidades, em um processo educacional em âmbito nacional. (P16)

É possível interpretar que, no fim de seu processo de recontextualização, P16 refocaliza o currículo nacional admitindo-o como marco global que deverá assumir características diversas nos contextos específicos de cada região, por meio das comunidades epistêmicas locais:

Dessa forma, acredito que uma alternativa razoável em caso de divergência após o estabelecimento de currículos definidos por comunidades epistêmicas globais ou nacionais seria a abertura para a análise deste currículo por parte das comunidades epistêmicas locais, umas vez que elas "são capazes de reinterpretar os marcos globais com base em suas concepções e interesses", buscando-se, assim, estabelecer abordagens particulares ao conteúdo nacional que contemplem as características específicas de cada região do país. (P16)

P17 dá prosseguimento ao destaque para as comunidades epistêmicas, iniciada por P16, e reposiciona estes grupos ao colocá-los em oposição aos professores, que reproduzem o conhecimento. A esses dois grupos, P17 associa também finalidades educacionais opostas. Ao mencionar "temos que nos posicionar", P17 deixa sua posição em aberto no comentário.

As comunidades epistêmicas são consideradas os produtores de conhecimento, que elaboram as novas diretrizes e os parâmetros curriculares. [...] De um lado, temos os mentores do conhecimento dentro de uma orientação política. Na outra ponta, estamos nós, professores, que reproduzimos o conhecimento. Temos que nos posicionar. Estamos reproduzindo o conhecimento, instigando o aluno a pensar e a questionar, ou simplesmente formando tecnicistas para atender ao mercado? (P17) 
Entretanto, a partir deste ponto, P17 destaca do texto a ideia de que

[...] o currículo nacional permanece porque, mais do que associado a uma política neoliberal, faz parte de uma política em defesa da cultura comum. $O$ fato de, na atualidade, essa política estar sendo articulada aos interesses de mercado, por causa da influência de marcos globais, não impede que seja defendida por outros grupos de interesses diversos. (LOPES, 2006, p. 154)

Assim, reposiciona o texto enfatizando a oposição entre a formação do ser integral e a formação para o mercado, expondo sua crítica ao que seria o objetivo do currículo nacional:

Temos uma obrigação de seguir o currículo nacional por uma questão legal. No entanto, quando analisamos o currículo a partir da formação de indivíduos éticos, com ampla capacidade criativa, total liberdade para o pensar e, sobretudo, indivíduos críticos quanto ao mundo e quanto a si mesmo, acredito que o currículo nacional trata da temática ideal que deve nortear os professores, mas falha na formação do ser integral. Estamos formando técnicos para um mercado de trabalho que exige o aprendizado de habilidades diversas. Verifico a ausência da crítica à cultura aprendida. Uma espécie de contracultura que, para aqueles que viveram o regime da ditadura militar, estava em constante exercício. Representa aprender as habilidades que a sociedade de mercado exige, não deixando de questionar o porquê desse conhecimento, como foi produzido, qual a razão que levou a produzi-lo, quais os impactos na vida de cada indivíduo e na sociedade. (P18)

Inicialmente, P18 reposiciona a ideia de currículo nacional presente no comentário de P17 agregando a ela os conceitos de igualdade e direcionamento, ainda que admita falhas na formação de um ser integral. Seu processo de recontextualização reafirma o currículo nacional e as necessidades de relacioná-lo com as realidades locais:

Conforme dito por muitos colegas, um currículo nacional se faz necessário, seja para dar condições de igualdade a todos (ou o mais próximo possível de ser para todos), mas também por questões legais, de referência, como dito por P17. É claro que, ao analisarmos o currículo mais profundamente, perceberemos que ele falha na formação de um ser integral, nosso aluno. Acredito que seja neste ponto que cada professor faz a diferença, independentemente da sua região de atuação. O currículo serve para nortear nosso trabalho, dar um direcionamento, mas devemos sempre vinculá-lo com a nossa realidade; é claro que neste ponto a formação do professor é importantíssima. Porém, ao mesmo tempo, devemos dar condições a todos de forma igualitária, e não excludente, como é nos dias atuais. (P18)

Em seguida, P18 destaca - segundo ele, com base em seu comentário um trecho do texto, já citado no fórum, no qual Lopes (2006) se refere a ideias de Williams sobre o currículo nacional:

Na perspectiva de Williams, para a construção de uma sociedade democrática, há a necessidade de uma cultura comum e de uma educação igualmente democrática capazes de superar padrões sociais e educacionais vigentes com base em uma estrutura de classes 
suposta como imutável. [...] Isso não significa, para o autor, que todos os indivíduos de uma dada sociedade compartilham da mesma maneira tal estrutura de sentidos, mas que o fato de se constituírem uma sociedade é, em parte, pelo compartilhamento de tal estrutura (LOPES, 2006, p. 136).

Após incluir este trecho no fórum, P18 justifica sua concordância com o autor e reconstrói as principais ideias do texto, até que reposiciona o currículo nacional agregando a ideia de nortear um conjunto mínimo de saberes que daria condições igualitárias e que representaria um referencial da qualidade mínima exigida. Recontextualiza, assim, o currículo nacional e ainda focaliza a necessária adaptação conforme as diferenças regionais:

Concordo com o autor quando afirma que, para a construção de uma sociedade democrática, há a necessidade de uma cultura comum e de uma educação igualmente democrática, capazes de superar padrões sociais e educacionais de um currículo nacional, pois se realmente constituímos uma sociedade é pelo fato de que compartilhamos de uma estrutura de sentidos, por isso um currículo nacional servirá para nortear um conjunto de saberes mínimo a todos e, consequentemente, para dar condições igualitárias a todos de um referencial da qualidade mínima exigida, mas é claro que sempre adaptando o currículo conforme as diferenças de cada região. (P18)

P19 reposiciona a ideia de currículo nacional relacionando-o a uma formação básica para todos, mas não consegue vislumbrar quais saberes estariam agrupados nesse currículo. No fim de sua recontextualização, apresenta um paradoxo, uma vez que conclui pela impossibilidade de se chegar a um currículo nacional. P19 também comenta sobre as comunidades epistêmicas locais, refocalizando o tema quando acrescenta a dúvida sobre a integração da visão dos professores nessas comunidades. Seu questionamento dá margem a interpretarmos uma desconfiança por parte de P19 em relação à participação dos professores nessas comunidades:

Bem, depois da leitura, pude entender um pouco sobre como funcionam os bastidores da definição de um currículo nacional e vi o quanto é complicado. Concordo com a colocação de alguns colegas na questão de um currículo mínimo que vise oferecer uma formação básica a todos. Porém, o que seria o básico? Acho que esta definição, para um país como o nosso querido Brasil, seria muito difícil. Outro ponto interessante foi a questão das comunidades epistêmicas, que merecia um pouco mais de discussão, pois o assunto é um pouco complexo. Conforme comentou P13, como a nossa visão/opinião, que estamos dentro de sala, chega até essas comunidades que atuam no diagnóstico tanto quanto na proposição das metas? (P19)

P20 dá continuidade à discussão sobre as comunidades epistêmicas, repetindo o questionamento e o posicionamento de P19 sobre a participação da visão do professor nas comunidades epistêmicas. Como se tentasse responder a esse questionamento por meio de um exemplo, agrega ao tema um trecho do texto a respeito das Orientações Curriculares para o nível médio de ensino (BRASIL, 2004), que, segundo Lopes (2006), apresentaria pequenos aperfeiçoamentos em 
relação aos PCNEM de química e física. Reposiciona esse trecho por meio de uma pergunta: "Pequenos aperfeiçoamentos no ensino de física?"; colocando em xeque a possibilidade de um pequeno aperfeiçoamento ser suficiente para dar conta da desatualização dos conteúdos ensinados hoje nas escolas e, ao mesmo tempo, evidenciando a não participação da visão dos professores na elaboração do documento. Assim, ao ressaltar a importância da adequação da reforma curricular às inúmeras mudanças observadas na sociedade atualmente, P20 recontextualiza criticamente a proposta oficial em função da necessária atualização dos conteúdos de física nas salas de aula:

Comentando o que o P19 postou, concordo com o comentário do professor P13 sobre nossa visão/opinião: Ela chega até essas comunidades epistêmicas? Tanto que me chamou a atenção o penúltimo parágrafo da página 12 do documento: "Os documentos dessas orientações curriculares para o nível médio de ensino (BRASIL, 2004) variam entre apresentar: a) pequenos aperfeiçoamentos aos parâmetros já existentes, caso dos documentos de química e física, por vezes destacando a dificuldade de implantação, como no caso de filosofia e artes; b) novos parâmetros, como nos casos de história, linguagens, literatura e matemática; c) questões para o debate sobre a produção de novos parâmetros, caso da educação física, da biologia e da geografia; d) crítica aos parâmetros, caso da sociologia.” Pequenos aperfeiçoamentos no ensino de física? A física que é ensinada em sala é a do século XIX, e estamos no século XXI! Muita coisa evoluiu nesse tempo! (P20)

\section{CONCLUSÕES}

A análise dos processos de recontextualização realizados pelos professores a partir da leitura do texto acadêmico permitiu identificar dois posicionamentos em relação ao currículo nacional e à proposta curricular oficial: recontextualizam o texto e aceitam este projeto e/ou a proposta; ou o recontextualizam e criticam este projeto, opondo-se à ideia de um currículo nacional. Não conseguimos identificar o posicionamento final de um dos professores.

A maior parte dos professores (13 de 19) defende o currículo nacional - ainda que recontextualizado -, por exemplo, enquanto: referencial de qualidade mínima; medida do conhecimento e do desenvolvimento do povo brasileiro; instrumento para compreensão das dificuldades sociais; possibilidade de ascensão social; dever do Estado e direito de todos; forma de abstrair o conhecimento que é oferecido em diferentes realidades; universalização do conhecimento; e democratização dos conhecimentos sedimentados pela humanidade. Seis professores consideram que a proposta precisaria contemplar as culturas locais e, assim, atender às diversidades sociais e culturais da comunidade onde atuam. Também foi refocalizada a ideia de que, antes de se tornar oficial, esta proposta deveria ser recontextualizada pelas comunidades epistêmicas locais, pois só assim contemplaria as diferentes necessidades regionais. Dois professores defenderam a participação dos docentes de nível médio nessas comunidades. 
Apenas seis professores se posicionaram contra a proposta curricular oficial, tendo criticado justamente seu "suposto" caráter de currículo nacional. Segundo estes professores, ao contemplar somente uma parcela da cultura ou a realidade de poucas escolas brasileiras, o currículo nacional se apresenta como uma seleção da cultura das classes dominantes, além de atuar como regulador do trabalho docente.

Assim, ainda que o grupo de professores pesquisados tivesse representantes de todas as regiões do país, foi possível perceber certa homogeneidade a favor da instituição de um currículo nacional. Aproximamos esta posição à assumida pela maior parte das pesquisas em ensino de física, que defende os PCNEM e tende a usar os parâmetros como justificativa para seus trabalhos. Seguindo Bernstein (1996), quando os campos recontextualizadores oficial e não oficial se associam e, portanto, menor é a autonomia entre eles, mais facilmente se exerce o controle sobre o que acontece nas escolas. A aceitação do currículo nacional de física pela comunidade de pesquisa, e também pela maior parte dos professores pesquisados neste estudo, denota, assim, pouca autonomia relativa entre esses dois campos, o que enfraquece a direção questionadora dos padrões estabelecidos e as possibilidades de mudança no ensino de física.

Considerando que ainda são poucas as pesquisas que propõem uma reflexão sobre a proposta curricular oficial, recomenda-se que novos trabalhos discutam este tema, trazendo para o debate ideias mais críticas que permitam de fato aprofundar as questões envolvidas.

\section{NOTA}

${ }^{1}$ Recontextualização do currículo nacional para o Ensino Médio de física no discurso de professores.

\section{REFERÊNCIAS}

BERNSTEIN, B. A estruturação do discurso pedagógico: classe, códigos e controle. Petrópolis, RJ: Vozes, 1996.

BRASIL. Ministério da Educação, Secretaria de Educação Média e Tecnológica. Parâmetros Curriculares Nacionais para o Ensino Médio. Brasília: Ministério da Educação, 1999.

- Ministério da Educação, Secretaria de Educação Média e Tecnológica. Orientações Curriculares Nacionais para o Ensino Médio. Brasília: Ministério da Educação, 2004.

LOPES, A.C. Os Parâmetros Curriculares Nacionais para o ensino médio e a submissão ao mundo produtivo: o caso da contextualização. Educação e Sociedade, vol. 23, n. 80, p. 386-400, 2002.

Políticas de currículo: mediação por grupos disciplinares de Ensino de Ciências e Matemática. In: MACEDO, E.; LOPES, A. C. (Eds.) Currículo de Ciências em debate. São Paulo: Editora Papirus, 2004.

Quem defende os PCN para o Ensino Médio? In: LOPES, A.R.C. \& MACEDO, E.

(Orgs.). Políticas de currículo em múltiplos contextos. São Paulo: Cortez, 2006. (Série Cultura, memória e currículo). 
MAINARDES, J.; STREMEL, S. A teoria de Basil Bernstein e algumas de suas contribuições para as pesquisas sobre políticas educacionais e curriculares. Revista Teias, v. 11, n. 22, p. 1- 24, 2010.

REZENDE, F; OSTERMANN, F. A prática do professor e a pesquisa em ensino de Física: novos elementos para repensar a relação. Caderno Brasileiro de Ensino de Física, Florianópolis, v. 22, n.3, p. 316-337, 2005.

RICARDO, E.C. Implementação dos PCN em sala de aula: dificuldades e possibilidades. Física na escola, v. 4, n. 1, 2003.

RICARDO, E. C.; ZYLBERSZTAJN, A. Os parâmetros curriculares nacionais para as ciências do ensino médio: uma análise a partir da visão de seus elaboradores. Investigações em Ensino de Ciências, v. 13, n.3, p. $257-274,2008$.

TARDIF, M; LESSARD, C. O trabalho docente: elementos para uma teoria da docência como profissão de interações humanas. Petrópolis, RJ: Vozes, 2008.

Data Recebimento: 06/06/2013

Data Aprovação: 10/09/2014

Data Versão Final: 13/11/2014

\section{Contato:}

Flavia Rezende

Universidade Federal do Rio de Janeiro, llha do Fundão, Centro de Ciências da Saúde, Núcleo de Tecnologia Educacional para a Saúde (NUTES)

Bloco A, sala 26, Rio de Janeiro, RJ, CEP 21949-900. Email: flaviarezende@uol.com.br

\section{ERRATA}

No artigo "Recontextualização do currículo nacional para o ensino médio de física no discurso de professores" publicado na Revista Ensaio V16-3

\begin{tabular}{|c|c|c|c|}
\hline Página & Linha & Onde se lê & Leia-se \\
\hline 1 & Coluna de autores & $\begin{array}{l}\text { Roberta Comissanha * } \\
\text { Josiane de Souza ** } \\
\text { Fernanda Ostermann } * * * \\
\text { Flávia Rezende } \\
* * * *\end{array}$ & $\begin{array}{c}\text { Flavia Rezende * } \\
\text { Fernanda Ostermann ** } \\
\text { Josiane de Souza } * * * \\
\text { Roberta Comissanha de } \\
\text { Carvalho } * * * *\end{array}$ \\
\hline
\end{tabular}

